\title{
Purposive Action Is a Genuinely Sociological Perspective
}

\author{
Erhard Friedberg \\ Centre de Sociologie des Organisations, SciencesPo, Paris, France
}

\section{Email address:}

e.regenhart@gmail.com

\section{To cite this article:}

Erhard Friedberg. Purposive Action Is a Genuinely Sociological Perspective. Advances in Sciences and Humanities. Vol. 5, No. 6, 2019, pp. 171-179. doi: 10.11648/j.ash.20190506.16

Received: October 18, 2019; Accepted: December 18, 2019; Published: January 6, 2020

\begin{abstract}
In recent years, the theme of actors and agency has made a notable reappearance in the neo-institutionalist literature, in relation in particular to what has been called institutional entrepreneurship and institutional entrepreneurs. Two recent books by M. Granovetter on the one hand, Neil Fligstein and Doug McAdam on the other, can be seen as significant examples of this "return of the actor" in American sociology. The troubling conceptual inconsistencies they contain, however, also document the incomplete integration of an action perspective into what basically remains a neo-institutionalist framework, giving epistemological priority to structure over action. This paper aims to highlight the most important of these inconsistencies and sets out to interpret them as a sign of how sociologists position themselves and their discipline in the wider field of social science, and in particular in relation to economics. It concludes by suggesting that in order to go beyond such methodological and conceptual confusion, we need to get away from a substantialist, decontextualized view of the actors' identities and rationalities, and replace it with a relational conception of the actors' identities and rationalities, in which their behavior would be considered to be attributes not of the actors, but of the local relational configurations and the stable patterns of transactions maintained by them.
\end{abstract}

Keywords: Methodological Individualism, Instrumental Action, Pragmatic Actors, Skilled Actors, Institution, Relational Sociology

\section{Introduction}

In recent years, American sociology has witnessed what could be called a «return of the actor". With the rise of the neo-institutionalist perspective and analyses ${ }^{1}$ in the late seventies and eighties of the last century, this concept had practically been erased from mainstream sociological publications. Social dynamics and social change used to be analyzed as the result of impersonal forces and trends, with imitation being a favorite explanatory variable. More recently, however, the theme of actors and agency has made a notable reappearance in the neo-institutionalist literature of the last ten years, in relation in particular to what has been called "institutional entrepreneurship and institutional entrepreneurs" (Battilana/Leca/Boxenbaum [Battilana/Casciaro [2] Beckert [3] and Beckert [4], Bergeron

1 The notion seemed to have been anathema to the heart of the neo-institutionalist perspective: this point was driven home to me when, in an interview I videotaped with him in 2006, Woody Powell mentioned that he used to cross out the word whenever it turned up in his students' term-papers.
[5] Bergeron Castel [6] Bergeron/Castel/Nouguez [7] Castel/Friedberg [8] Fligstein/McAdam [9] Hall [10] Skowronek/Glassman (Ed.) [11] And with this shift in focus, the discussion about the limits of the influence of institutional frames on the actors' behavior, about the actors' reflexivity (reflexive capacity) and his or her "reflexive moment", and about the impact in return of the actors' behavior on institutional frames have again become important themes on the sociological agenda.

Two important sociological books published in recent years, Mark Granovetter's Society and Economy [12] and Neil Fligstein and Doug McAdam's $A$ theory of Fields [13] can be seen as examples of this "return of the actor". The troubling conceptual inconsistencies they contain, however, also document the difficult and incomplete integration of an action perspective (or should one say an actor perspective?) into what basically remains a neo-institutionalist framework, giving epistemological priority to structure over agency. This in turn raises interesting methodological questions about sociology's troubled relationship with Max Weber's methodological individualism, which in turn could be 
interpreted as the symptom of a more general problem of how sociology as a discipline tries to position itself in the larger field of the social sciences.

This is, in short, the argument of this paper. In the first part, it will document, and comment on, the aforementioned conceptual inconsistencies. In a second part, it will then propose an interpretation of what these inconsistencies might tell us about the state of sociology as a discipline in the wider field of the social sciences. It will conclude by suggesting that in order to go beyond such conceptual inconsistencies and fuzziness, it is necessary for sociology to free itself of a substantialist, decontextualized view of the actors' identities and rationalities, and replace it with a relational conception, in which observed behavior would be considered to be attributes not of the actors, but of the local relational configurations and the stable patterns of transactions maintained by them. The article ends by discussing some of the implications of such a change in perspective.

\section{Conceptual Inconsistencies of the Figure of "Pragmatic Actors" and "Skilled Actors"}

The reader of Mark Granovetter's Society and Economy: Framework and Principles [12], is struck by the strong contrast and discontinuity in tone (and (reasoning) presented in the first four and the last two chapters of the book. And N. Fligstein and D. Mc Adam's A Theory of Fields [13] strangely echoes such conceptual hesitation and confusion.

\subsection{The Fuzziness of Granovetter's "Pragmatic Actors"}

The first four chapters are clearly structural in tone. One can find some vague references to something called a "pragmatic methodology" without any further elaboration of what that would be. In chapter one, methodological individualism as an alternative to more holistic or structural conceptions is brushed aside without much serious analysis. On the ground that it draws on an under-socialized, atomistic conception of the actor it is quickly disqualified as an individualistic mode of explanation that could be assimilated to a psychological approach and/or to rational choice theory ${ }^{2}$. Chapters two, three and four then present norms and obedience to norms, trust and power as phenomena which structure action without being structured in return, without any reference to the actions (the behavior) of the actors who decide to obey, to trust or to distrust, to exert power or try to evade power.

In the last two chapters, the tone changes drastically. The most visible sign of the change in tone is the sudden and

2 Here is the passage I am referring to: «The methodological individualist might begin by supposing that some individuals are bound to be powerful because they have characteristics or resources that make it highly likely they will create dependence, engender compliance by conveying legitimacy or persuasively shape the economic agenda. [5]» (p. 103). This is clearly a caricature of methodological individualism in sociology, and even of some of the more interesting rational choice literature. massive introduction of the hitherto never discussed "pragmatic actor". In chapter five, this notion appears out of nowhere, and nothing in the preceding chapters has prepared the reader for its introduction. And its importance is further emphasized by the use of the terms "action" in the title of chapter six. In this chapter, we are encouraged to see institutions (contrary to the norms in chapter two) "as cultural, structural and normative patterns assembled by actors from a variety of existing materials" [3] (p. 147) and to look at actors as "bricoleurs" of institutions")

While the notion (concept) of the "pragmatic actor" clearly occupies a central position in the last two chapters of Society and Economy, Granovetter [12], who offers many definitions in other parts of the book, never really defines the nature or the identity of this "pragmatic actor". The reader has to look for the many indirect indications contained in the descriptions of what these "pragmatic actors" do. On p. 171, we thus learn that they are not prisoners of institutions, since they are active in relation to them. Therefore they are not completely embedded, but are able to maintain some distance/reflexivity. One also is told that these actors somehow evade institutional constraints and scripts or "play with them" by choosing ("settling on" in Granovetter's words) one particular institutional approach in order to solve a problem they face. We are also told that they are syncretic, meaning that they tinker the solutions by assembling heterogenous, if not contradictory institutional elements available in "alternative menus".

We can therefore conclude that these actors are intelligent, and, if we take the word seriously, that they have at least some reflexive capacity, that these actors are therefore not only pragmatic, but also skilled actors (as N. Fligstein and D. McAdam [2] would call them). Now then, what precisely is the meaning of the adjective "pragmatic"? If its use is judicious, it implies to the least that these actors have a practical mind, meaning that they are not ideologues, but respect in their actions some principle of reality (of a reality as they see it with all possible cognitive biases). Without wanting to push this interpretation too far, one can then with good reason also suppose that these actors will, to some extent, be opportunistic. They don't do just anything, but something that makes sense, not necessarily in general, but for them in particular, something that seems appropriate given the circumstances as they see them. Without making the actors amoral, one can therefore also expect that their "pragmatism" will push them to act opportunistically (within limits). And one can further suppose that endowed with a practical mind, these actors will not act without some goals

\footnotetext{
3 «So here again, I lean toward the pragmatist epistemology that I have mentioned before, closely related to a depiction of actors as being syncretic, or engaging in what the French call "bricolage.» (p. 143-144). Granovetter [12] reiterates the same idea in a later section of the book as follows: «Actors who cast about for ways to deal with some problem, economic or otherwise, become aware of various approaches, where I use "approaches" as a way of talking about institutions as they appear to individuals. Roughly speaking, there are three alternative ways that they can settle on a particular institutional approach to help solve a problem...» (p. 171; emphasis mine).
} 
or objectives, and without considering, to the best of their ability, the consequences of what they are about to do. Whether we like it or not, their actions will therefore always be to some extent, consequentialist. However, in order to be able to evaluate the possible consequences of some action, one needs to have some idea about the desirable. It follows from all this that it is difficult to imagine the pragmatic actors without a certain idea (however vague and approximate) about what they would like to obtain by their action. This in turn means that they also have interests (whatever their nature). The actor's actions therefore will also always include some instrumental dimension, even though this is obviously only one among many dimensions.

Building on Granovetter's description of what they do, his "pragmatic actors" seem like twin brothers of the actors of methodological individualism, an analytical approach strongly rejected in the first chapter where it is disqualified as being part of atomistic and reductionist perspectives. But if the "pragmatic actors" are more than a mere figure of speech or more than just some stylistic formula, then one has to conclude that they are in fact endowed with all the attributes which in the first chapter are all criticized as being part of, or leading to, a reductionist, atomistic and under-socialized perspective of the individual. Incidentally, the reader has trouble understanding why these «pragmatic actors» make their appearance only in chapter five. If the instrumental dimension is present in their choice of the institutional material that they assemble in their solutions, then why would that same dimension not characterize their relations to norms ${ }^{4}$, why would it not structure their decision "to trust" or "distrust". And if in chapter five, these "pragmatic actors" are granted some autonomy (or margin of freedom) in their relations to institutional frames, why is that autonomy not included and analyzed in the chapter on power, where it would have led Granovetter to a richer and more differentiated and less unilateral, less vertical and less structural conceptualization of power, which would analyze it as an unbalanced but also reciprocal exchange relation, i.e. in its vertical as well as horizontal forms.

Asking these questions does not have us fall back into some atomistic reductionism which according to Granovetter, characterizes the under-socialized vision of the actor. They follow from applying and taking seriously the attributes of the pragmatic actors as they emerge from Granovetter's description of their actions in the second part of the book.

So we are faced with the following alternative: either the «pragmatic actors» of the second part are only an empty rhetorical form and a simple figure of speech, void of any concrete content. If this is the case, then the description of what these actors are doing has no concrete basis or corresponds to nothing in reality: they would be nothing more than metaphors or figures of speech. Or the notion of "pragmatic actors" indeed describes some concrete actor with all the attributes that I have listed taking them from a series

4 Surprisingly, no reference is made in this chapter to themes such as ex-post rationalization or cognitive dissonance. of descriptions in the second part of the book. In that case, there clearly is a strong inconsistency between the epistemological posture underlying the first and the second part of the book. This inconsistency is quite perceptible to the reader. It is, however, never made explicit. It is passed over and never thought through with all its implications.

\subsection{The Strangely "Non-instrumental" Nature of Fligstein and McAdam's "Skilled Actors"}

Such conceptual inconsistencies coming out of the pen of a Master of the art like Mark Granovetter is troubling enough. It seems to echo a more general reluctance of mainstream sociology to recognize agency, i.e. the possibility of autonomous action on the part of (individual) members of society and to think through all the implications this recognition would have for our way of understanding the social world. The presence of similar and even more disconcerting conceptual incongruities in N. Fligstein and D. McAdam's A Theory of Fields [13], a book that can be considered quite emblematic of the "return of the actor" in sociological theorizing, is a second case in point.

In the first part of their book called "Micro-foundations", Fligstein and McAdam present what they call «skilled actors» as a distinct category of individuals (members of society). They are different insofar as they are endowed with the reflexive capacity necessary to gain some cognitive autonomy and critical distance in respect to the institutional frames and structures of the social fields in which they find themselves (should we say in which they are «embedded»?). And lastly, they are endowed with the capacity to define projects and develop collective meaning-making enabling them to enroll others and induce collective action. Remember that I am quoting from the chapter on the "Microfoundations" of their theory, the chapter which presents what M. Granovetter would have called the nullhypothesis on which Fligstein and McAdam's book is built. P. 49-50, we learn that the existential function of the social (of collective action which they seem to define as "collective meaning making" [13]) makes it impossible for individuals not only to withdraw from collective action and their commitments, but also to merely discriminate among these commitments between those that they would like to continue and those that they would like to terminate, between those in which they would like to put all their energy and those in which they might want to be just passive participants. This is why, according to Fligstein and McAdam, Mancur Olson's dilemma of collective action [14] does not apply in their framework, as the options of exit or «free-riding" don't exist anymore and therefore need not be considered ${ }^{5}$.

\footnotetext{
5 Here is the exact quote: «This brings us to our second point. In rational actor models, individual participation in collective action can never be taken for granted. Indeed, the default option for rational actors is to refrain from collective action and resist collective commitments that might impede their ability to realize their ends. This tendency to "free ride" can only be overcome, we are told, when organizers provide selective incentives that make it rational for individuals to affiliate within the group or action in question. In short, collective entanglements only make sense if they aid the individual in realizing narrow instrumental aims.
} 
One can leave aside the strangely functionalist nature of their argument. It must however be stressed that it creates a paradox or to say at least a theoretical tension, which echoes similar tensions observed in Mark Granovetter's book. On the one hand, Fligstein and McAdam present strategic action of «skilled actors» as the main driving force of, and necessary condition for, collective action. A few lines later, however, these very same actors, who, as strategic and "skilled" actors, are by definition endowed with interests, are denied any autonomy and capacity to choose among their commitments. Yes, they are skilled, but at the same time, their autonomy and their capacity to act opportunistically and instrumentally, to select and measure their commitments ${ }^{6}$ are, by definition, limited, if not denied. These limits are given ex ante and fixed, as they are rooted in the "existential function of the social". One hand has taken away, what the other hand had granted: in the end, the individual is not autonomous but inhabited (should we say invested?) by the social which is stronger than their "narrowly instrumental" strivings highlighted by rational choice theory". The social, and its discipline, sociology, are safe from contamination by economic reasonings.

\section{Putting Such Conceptual Confusion into Perspective}

Les us sum up what we've seen so far. It is certainly perplexing to see that a seasoned sociologist who with the title of his book clearly positions himself within the intellectual heritage of Max Weber and his opus maximum, Economy and Society, would remain as reluctant to situate himself within the Weberian paradigm of a sociology of action, and would so adamantly refuse the perspective prolonging this paradigm then and today, i.e. methodological individualism. Our perplexity increases when we compare Society and Economy with Granovetter's earlier publications which undoubtably make use of that paradigm. And our perplexity grows further when in A Theory of Fields we are faced with a theory which proposes and builds on the concept of a skilled and strategic actor, and then argues that the

Our stress on the existential functions of the social leads us to embrace a starkly opposing view. For us, affiliation with groups and other collectives is a highly desired end in and of itself. Ultimately, the central sources of meaning and identity in our lives can only be conferred by collectives. Accordingly, much of our social skill is deployed in the service of fashioning and safeguarding these collective existential projects.» (p. 49-50; emphasis mine).

6 If words have a meaning, such capacities are, by definition, part of what can be called "strategic action".

7 Fligstein and McAdam [13] express some implicit moralism by always associating the adverb "narrow" with term "instrumental action", the implication seemingly being that instrumental action is in itself morally inferior because of its «narrowness". In order not to be narrow, commitments in collective action would, for no understandable reason, would have to be non-instrumental, i.e. pursue no goal and be totally disinterested. I don't know of any collective action that would be non instrumental and completely disinterested. Activists in the service of collective action are never disinterested: their action aims to be instrumental if only in the pursuit of what they see (or have labeled) as the collective or the public interest. constraint of the "existential function of the social" not nullifies the skills of this very actor (his or her reflexive capacity according to the very definition of Fligstein et McAdam), by disabling him from selecting his or her social commitments among the different possibilities his or her situation offers.

The least that could be said is that we are faced with, let's call it, a conceptual fuzziness and confusion which betrays some sort of theoretical hesitation. How are we to understand this hesitation? Is its significance limited to the specific books being examined, or is it the sign and symptom of more general problems that sociology as a discipline is facing? I would be tempted to opt for this second interpretation. My reasoning behind this hypothesis would look like the following: On the one hand, sociology is experiencing an internal crisis, with the credibility and legitimacy of the predominantly holistic and neo-institutional framework of mainstream sociology becoming increasingly vulnerable in its attempt to account for empirical reality. On the other hand, in the wider field of social sciences, economics ${ }^{9}$ and other social sciences are on the offensive. In reaction and as a consequence, sociologists are tempted to reaffirm the status and position of sociology as a discipline within this wider field of social sciences, with sociology being on the defensive and attempting to differentiate itself from economics as best it can, by dissociating from methodological individualism considered to be the analytical posture of economics ${ }^{10}$ and therefore inappropriate for the study of the "social with all its complexity".

Two quotes from different parts of Society and Economy [12] seem to point in the direction just outlined. At the beginning of Chapter five, Granovetter states that "Sociology as a discipline is distinctive in a number of ways, but I think that the most significant is its emphasis on all major aspects of life (economic, political, social, religious/ideological and others) and in its assumption that not one of these aspects has a causal priority" (p. 135, emphasis by the author).

8 The existence of which I do not deny.

9 And in particular behavioral economics and other social sciences such as cognitive psychology, neurosciences, i.e. sciences of the individual, sciences without relations.

10 Seen from this perspective, the paradigm of methodological individualism suffers from two handicaps. On the one hand, it can easily be understood as a method and an analytical posture associated with economics (today as well as historically, as it is known that Max Weber developed his paradigm in relation to the work of L. von Mises (one of the masters of the Vienna school of economics) with whom he corresponded at the time and whose works he was more than familiar with). Adopting this paradigm would in this perspective amount, for sociology, to lose its specificity as a discipline and to surrender to the imperialism of economics and its Trojan horse, Rational Choice Theory. On the other hand, there might also be some ideological dimension behind this disciplinary reasoning. It is indeed easy, even though incorrect, to present methodological individualism as a paradigm of the «right», as it is also associated with liberal thinkers such as, among others, F. von Hayek or Karl Popper, and more generally with the economists of the University of Chicago, strongly influenced by the Vienna school of economics and whose reputation as economic "liberals" and «neoliberals" is no secret. For sociologists who prefer to position themselves in a critical, not to say progressive political perspective, this could be, and in my mind certainly is, an additional motive to refuse the paradigm of methodological individualism. 
This quote echoes another one from the introduction in which Granovetter writes: "The Null-hypotheses typically contain assumptions on "human nature", and because "nurture" trumped "nature" in most twentieth century social science, it looks old-fashioned to make such assumptions explicit; yet they are pervasive, even when barely whispered. The Null-hypotheses of economists and sociologists differ markedly: most economists explain by assuming that individuals pursue their interests, guided by quantifiable incentives. While few endorse the stereotypical rational calculator, homo economicus, models based on individual interests and explicit or implicit calculations still take priority over those that would invoke more complicated "social factors" not amenable to simple and elegant models." [12] (p. 3)

These two quotes express two contradictory constraints. The first (p. 135) is close to Granovetter's heart, as we can find it repeated several times in the book. It refers to his constant preoccupation to clearly differentiate sociology from economics, a preoccupation that seems all the more crucial as economic sociology is, by its very object, always in danger of being contaminated by economic reasoning, and in particular by rational choice theory. In this regard it is important to reiterate that sociology refuses null hypotheses, because (1) it takes into account «more complicated social factors not amenable to simple and elegant models» (p. 3), and because it is characterized by (2) "its emphasis on all the major aspects of economic, political, social, religious/ideological and others...life" (p. 135, emphasis mine), none of which can claim to have causal priority over the others, but which all together structure the situation and exert their causal force on behavior. In other words, all of these aspects exert their pressure on the actors from the outside and together explain their behavior. This strongly evokes something like a multifactor determinism which, like Durkheim in his days, is looking for the causes of behavior in «more complicated social factors» which are external to the individuals or, to use another word, of the actors. However, if taken too literally, such an approach leads to an empirical dead end. Empirical observation clearly demonstrates that such multi-factor determinism is not only unable to account for social reality, but also omits to reflect on the reciprocal impact of the behavior of the actors on those social factors which, under closer scrutiny, seem much less intangible than what a strict application of a holistic or durkheimian perspective would have one expect.

This is where the «pragmatic actor» comes into play. Its evocation gives the impression of realism to analyses of which the overall perspective is unchanged. Like in a magic garden, one now reads about «institutions» being tinkered in different directions. As a result, one finds oneself in a world that seems more realistic than it would be, had strictly durkheimian or neo-institutionalist programs been applied. All it needs is an occasional reminder of the force of these external forces and constraints, in order not to forget the limits that they impose on such tinkering. This makes it possible to have it both ways: Sociology is different from economics because it takes into account the "more complicated set of social factors" [12]. But it is also pragmatic, like the aforementioned actors, because it accepts to relativize and to moderate the determining forces of society and its institutions.

The introduction and description of «skilled actors» [13] who are by definition competent and strategic, would seem to make it more difficult to differentiate sociology from economics or at least from political economics. But the "existential function of the social" accomplishes the difficult task. It transforms strategic actors into non-instrumental actors, not driven by their interests and shot through with the social (at least by definition, if not in fact), able only to bargain their commitments within the strict limits drawn by the existential necessity to be part of the movement. These actors are strategic, because the book talks about strategic action and because it is difficult to imagine social movements without interests. But they are also totally social, totally driven by their (unconscious?) "need" to fulfill the existential function of the social which makes them worthy and legitimate objects of sociological inquiry.

In conclusion of this section, it is interesting to note the convergence in the argumentation of both books around the critique of the idea of purpose behind the actors' behavior and its implication, an understanding of action as being instrumental. Fligstein and McAdam argue that "skilled actors" are absorbed and driven by the "existential function of the social": their action therefore lacks any "narrowly" instrumental dimensions. Granovetter, in his line of reasoning, insists on the fact that sociology's specificity is to be seen in the fact that it does not explain behavior by the pursuit of interests (instrumental action), but by the combined force of "more complicated social factors".

\section{4. "Skilled" and "Pragmatic" Actors Call for a Different Explanatory Framework}

With all this in mind, I would be tempted to conclude that Granovetter's [12] "pragmatic actors" and Fligstein and McAdam's [13] "skilled actors" are somewhat fuzzy, and, in the end, empty forms of speech. It is not enough to add the word "actor" to the vocabulary to change paradigm. If they are real, they should become concrete, conceptualized as capable of making choices which then become the basic units of analysis. We should consider their behavior as the expression of their (bounded) rationality in the pursuit of some goal or target or purpose (to be discovered) that makes sense within the particular structure of their (immediate) context of action. It is not the combined force of the "more complicated social factors" which, operating in the back of the actors, produce and explain their behavior. This behavior should be conceptualized as the result of a "choice" made by them within the array of constraints characteristic of their situation or context of action as they perceive them with all their cognitive limits. And the inclusion of such "purposive", 
boundedly rational actors calls for a reconsideration of the status of their action which can be assumed to be instrumental, unless proven otherwise.

The analysis and explanation of economic action calls for a fundamental rethinking of the reciprocal relationship between agency and structure as well as a parallel rethinking of "structure". It cannot rely on some fuzzy compromise where the "pragmatism" of the actors (or the "existential function of the social") softens the unrealistic determinism of the overall analytical framework. The methodological consequence of such a rethinking of the analytical framework is most likely to be Max Webers "verstehende Soziologie" and its methodological individualism. However, accepting this consequence of the inclusion of some figure of a purposive actor - so the implicit reasoning seems to go -, would amount to surrender to the economists, to rational choice theory and their null-hypothesis, and to accept to analyze the actors' behavior as rational, intentional, interested and therefore instrumental, a perspective that (for no good reason and on the basis of a regrettable and restrictive misunderstanding of these words) sociologists seem reluctant to adopt, fearing to fall into the trap of an atomistic, individualistic, under-socialized if not unsocial vision of actors and society.

It is not quite understandable why we should let ourselves be trapped in what seems to me a dilemma easy to undo. And it is surprising that Granovetter seems to have fallen in the trap, because he could have easily escaped it on his own grounds. He only had to follow and flesh out the notion of network embeddedness which he himself had proposed in his seminal 1985 article $^{11}$ as a way to overcome both the underand over-socialized conceptions of human action and their shared atomistic view of the actors seen either as being placed in a social void and acting alone on the sole basis of their interests, or as passively executing the scripts written for (linked to) the sociocultural positions they occupy. Distinguishing "relational embeddedness" (the nature of the relations of ego to all the others) from "structural embeddedness" (the overall structure of the relations between all the members of ego's network) Granovetter considers the latter to be a crucial mediating mechanism between the micro and the macro-level.

\subsection{Network Embeddedness as a Way Out}

And a few pages later, he illustrates the force of this mediating mechanism by commenting on what had been in the 1970s an important controversy around the "rational peasant". In his 1976 book, J. C. Scott [16] had argued that in the pre-capitalist and thus pre-market peasant societies of South-east Asia, one could observe a moral economy based on a subsistence ethic which guaranteed to all families of a village a minimum of subsistence (based on some form of harvest-sharing) within the limits of the village's resources. The norm of reciprocity produced by this ethic was linked to the possibility of violent sanctions equally threatening for the

11 M. Granovetter [15] p. 481-510. rich and the poor. Samuel Popkin [17] in his book on the «rational peasant», argued on the contrary that the peasants he had observed in Vietnam were "rational actors" who did not lose sight of their personal interests in trying to improve their situations, and that therefore the village institutions which moral economists had emphasized, did not function all that well because of the conflict between individual and collective interests.

Having restated the terms of the argument, Granovetter goes on to show that both J. C. Scott and S. Popkin develop in fact a much more nuanced description which demonstrates that the reality is much more complex than the terms of the argument outlined above suggest. On the one hand, J. C. Scott observes that the moral economy he describes varies considerably from one region to the other. On the other hand, S. Popkin mentions an older system of harvest sharing in one part of Vietnam. By looking deeper into the background of this variance mentioned by both Scott and Popkin, Granovetter uncovers one additional element of the situation which makes him propose a different interpretation reconciling the two arguments. The additional element is the nature and characteristics of the networks which link peasants and landowners (the patrons) within the villages. Thus, in cohesive villages, there are few outsiders, peasants there personally know their landowners who reside in the villages and, are therefore sensitive to their reputation with the other members of the village. To say it differently: in villages where there exists some real interdependence between poor peasants and landowners who know each other personally and interact directly, the standards of the subsistence ethic will be observed and with it, the moral obligations deriving from it for the landowners. On the contrary, when economic and demographic circumstances have reduced the cohesion of the villages and the personal interactions between peasants and landowners (who tend now to live away from their land they have rented out), then these prescriptions are less respected and tend to be forgotten.

To sum up: Granovetter's interpretation [12] seems to demonstrate that it is the "structural embeddedness" of the peasants of South-east Asia, i.e. the characteristics and the structure of the networks both landowners and peasants are part of in different regions, which can explain why landowners behave "morally" according to the prescriptions of the subsistence ethic here, and why they seem to behave "selfishly" there, like the "rational peasants" described by Popkin. Both the "moral landowners" who respect the "subsistence ethic" and the "selfish" peasants who disregard it and pursue instead their personal interest, both are rational, both can be viewed as "pragmatic actors" (or boundedly rational actors) who derive or draw their rationality of action from different conditions of existence and within different frames of opportunities and constraints which make them see their interests in a different light. They are rational in the sense of Herbert Simon's bounded rationality, and they choose to behave in certain ways given their (always biased and limited) perception of the constraints and opportunities they face (including the reactions from their partners in their 
network). They have thus to be seen as reflexive and able to adjust their behavior to changing conditions of their immediate context of action - they are "skilled actors" to use Fligstein and McAdam's terms [13]. Their action can be seen as instrumental, meaning that it is in the service of interests as they define and pursue them, given the local structural conditions of action. And these interests are not given once and for all, they are contingent to the nature of the "structural embeddedness" defining and instituting something like a local order with its own normative regime, its own legitimacy, its own kind of rationality, its own powerstructure and an autonomous collective capacity of its own to produce and sustain cooperation as well as to sanction deviant behavior, to produce in other words behavioral patterns which are relatively disconnected (autonomous) from direct societal pressures.

What this means is that the landowners and the peasants in our example are not the same persons here and there, their identities vary as we switch from one place to the other: in different contexts of action, actors (individuals) will have to discover, and adjust to, different sets of constraints and opportunities, different patterns of responses from their partners to their own behavior in their new immediate context of action. Or it might also be the other way around. In bringing their routines to another place, they might also bring germs of change into their new location, if the conditions prevailing there enable them to sustain their behavioral routines in this new setting, and to induce their new partners to adjust and change their own routines. And it is most likely that this will never be an all or nothing game: the new rules of the game will be the result of what might look like the "bricolage" mentioned by Granovetter in the second part of his book.

\subsection{For a Relational Conception of Social Action and Actors}

Building on, and extending, Granovetter's [12] reinterpretation of the controversy around the "Rational peasant", this analysis explains why his "pragmatic actors" must remain fuzzy in the second part of Society and Economy. There is really very little that can be said about them per se without embedding them in the network they and their partners belong to, or to use Granovetter's terms, without contextualizing them by replacing them in what he would call their "structural embeddedness", or what I have called their "immediate context of action", with its unique set of opportunities and constraints

The implication is that we need to get away from a substantive decontextualized view of the actors' identities and rationalities. In such a view, the "moral" or "selfish" behavior of the landowners would be considered an all or nothing question, meaning it would be interpreted to express the individuals' dispositional and motivational structure, or their decision made once and for all to respect or to disregard the "subsistence ethic"12. Such a view obviously does not fit

12 In practice, this would amount to the same. the observed facts, as empirically we observe considerable variance in their behavior. However, if we replace this substantive view with a relational conception of the actors' identities and rationalities, this variance is easier to account for. In such a relational view, the "moral", non-calculating as well as the "selfish" and calculating behavior of the landowners would be considered to be attributes not of the actors, but of the local relational configurations and the stable patterns of transactions maintained by them ${ }^{13}$.

As a consequence, the "moral" (Scott [16]) or "rational" (Popkin [17]) behavior of the peasants observed in one context says nothing about their motivational structure or their dispositions and basic identities. It says very little about the lasting impact of these relational configurations and their transactional patterns on the deeper personality structures of the individuals involved. Of course, it could be argued that stable patterns of transactions within one type of relational configuration will not be without consequence on the participants' personality structure and identity, which in turn will enhance the stability and the reproduction of that particular configuration, generating in turn different path dependencies. But even such an impact should never be taken for granted, because this perspective underscores the plasticity, variability and radical unpredictability of the participants' behavior and emphasizes our inability as observers to know more than just bits and pieces of their identities.

What this boils down to is this: the analysis of economic action cannot be done without contextualizing it by reconstructing its "structural embeddedness", conceptualized as locally situated relational configurations producing stable patterns of transactions which are anchored in an underlying structure of power and interdependence generating its own constraints and opportunities, its own normative order capable of locally controlling deviant behavior as well as of mediating overall societal pressures.

In such a context, the actors of economic action (whether "skilled" or "pragmatic") can be fleshed out and become concrete without falling back into atomistic reductionism or the caricatures of rational choice models. Combined with "structural embeddedness", i.e. the analytical reconstruction of the properties of the networks linking actors and all their partners in relational configurations as defined above makes it possible, indeed calls for the use of what could be called a soft methodological individualism which evades the dilemma analyzed in the preceding section and which would follow a middle road between the two equally unsatisfying perspectives on social actors: on the one hand holism always in danger of ending up in a sociologistic", over-socialized" conception of humans as the passive bearers of general social norms and societal institutional prescriptions, and on the other side the "hard", decontextualized and under-socialized conception of intentional, utility maximizing economic action based on a

13 The analytical orientation sketched out in this section shares many features with the orientations presented in M. Emirbayer's article of 1997 [18], while remaining within the paradigm of methodological individualism rejected by Emirbayer's Manifesto. 
reductionist anthropology of humans as rational, intentional and utility maximizing in all circumstances, a view which certainly is not borne out empirically.

It does so by recognizing the relative autonomy (reflexivity) of individuals in relation to the different relational configurations (local orders) they are part of, the plurality of which is the source of their capacity as social actors to generate the very structures that constrain them. Structural embeddedness and the local orders it sustains, will be understood here as simultaneously producing the actors and their action and being reproduced by them and their action ${ }^{14}$ Actors and structure, while being analytically distinct categories, are here reciprocally linked in mutual, non-identical reproduction not of society as a whole, but of local, i.e. partial orders. The moral economy is not an all or nothing question. Within it, different normative regimes, different relational constructs between peasants and landowners co-exist. The empirical observation of the respect of the subsistence ethic in particular places does not authorize to draw conclusions about the economy in general, or about the personalities of the involved people; it does not provide the basis for moral judgements, it only informs us about the properties of particular contexts of collective action and their institutional structure whose impact is limited to these particular contexts. Relations of mutual solidarity are not constructed in a social void, they need specific relational constructs to generate and sustain them. Moreover, actors participating in such relations are simultaneously always part of other relational constructs or "games" whose very structure may provide them with some distance towards these obligations of solidarity and enable them in the end to break away and go their own way. They are never just driven by it: respecting the subsistence ethic is the product of a behavioral choice.

Contextualization of economic action within its always specific relational configurations is necessary because it does not take place in a homogenous, unified and continuous social structure, but in a fragmented social and institutional fabric which is made up of a great number of partial regulations, the consistency, homogeneity and hierarchization of which are never complete. Actors are parts of many "games" each of which exerts pressures on their respective rationalities and contributes to the formation of their identities which must therefore be considered unfinished, open and potentially unstable.

The relational configurations at all levels of society contribute to forge the identities of social actors. Moreover, all these socialization processes are never-ending processes which take place at all levels of social action and naturally feed-back on each other. The direct implication here is that the impact of any particular relational configuration or local order can never be determined beforehand, just as the identities of social actors cannot be reduced to their actual behavior in a given context or configuration: it should much rather be understood as an unknown continent of latencies and potentialities. In other words, the "social skills" Fligstein

14 This is why the contextualization of that action is indispensable. and McAdam [13] talk about, are not the privilege of some super-actors who possess them from the beginning because they were born with them: they need both actors and relational configurations to unfold, and they cannot be separated from either.

The normative implication of all these considerations is that maybe as sociologists we should stop moralizing about issues and stop talking about them in moral terms. There is nothing per se "narrow" in instrumental rationality. Altruism and generosity just as opportunism and calculative rationality may raise moral questions and issues on the individual level, but they are not a problem of dispositions to be created or inhibited at will. They are inseparably the generator and result of the relations through which, locally, collective action is built, as well as of the governance by which it is maintained in operation.

\section{Conclusion}

To conclude it seems obvious that social action is purposive. Contrary to what contemporary sociology seems to think, purposive action can be analyzed from a sociological perspective, and does not imply the use of a rational actor perspective. Neither does it condemn sociology, as Granovetter [12] seems to think in his latest book, to adopt an atomistic perspective. Embedding actors in their structural networks and explaining their actions as a rational, instrumental attempt to manage their interests to the best of their capacity within the constraints of these networks, is a genuinely sociological perspective which owes nothing to rational choice theory. Trying to artificially base the originality and autonomy of sociology in regard to other disciplines of the social sciences, (in particular economics), on the refusal of the idea of purposive, even instrumental action on the part of boundedly rational actors pursuing interests of their own when engaging in collective action within the constraints of their relational embeddedness, is bound to end in conceptual fuzziness that does not help to establish sociology as a legitimate as well as useful discipline in the wider field of the social sciences.

\section{References}

[1] Battilana J./ Leca B./Boxenbaum E. (2009) How Actors change Institutions: Toward a theory of Institutional entrepreneurship. Academy of Management Annals, 3/1, p. 65-107.

[2] Battilana J./ Casciaro T. (2013), Change Agent, Networks and Institutions: A Contingency Theory of Organizational Change, Harvard Business review, 91/7-8, p. 62-68.

[3] Beckert J., Agency, Entrepreneurs, and Institutional Change. The Role of Strategic Choice and Institutionalized Practices in Organizations, Organization Studies, 1999, vol. 20, $\mathrm{n}^{\circ}$ 5, p. 777-799. 23.

[4] Beckert J. (2010), How do fields change? The interrelations of institutions, networks, and cognition in dynamics of markets, Organization studies, vol. $31, \mathrm{n}^{\circ}$ 5, p. 605-627. 
[5] Bergeron H. (2018), Entrepreneuriat institutionnel et structures sociales, Dossier préparé en vue de l'obtention de l'habilitation à diriger des recherches en sociologie (Vol. 2), (sort of a second $\mathrm{PhD}$ for full professorship), Paris, Institut d'Etudes Politiques de Paris (SciencesPo Paris).

[6] Bergeron H./Castel P. (2015) Les habits neufs du néoinstitutionalisme, L'Année Sociologique 65/2, p. 23-61.

[7] Bergeron H., Castel P., Nouguez É. (2011), Un entrepreneur privé de politique publique. La lutte contre l'obésité, entre santé publique et intérêt privé, Revue française de science politique, vol. $61, \mathrm{n}^{\circ} 2$, p. 201-229.

[8] Castel P., Friedberg E., Institutional Change as an Interactive Process. The Case of the Modernization of the French Cancer Centers, Organization Science, vol. 21, n 2, p. 311-330.

[9] FligsteinN. / McAdam D. (2011), Toward a General Theory of Strategic Action Fields, Sociological Theory, 29/1, p. 1-26.

[10] Hall. P. (2010) Historical Institutionalism in Rationalist and Sociological Perspective, in Mahoney J./Thelen K. (Eds.) Explaining Institutional Change: Ambiguity, Agency and Power. Calbridge, Cambridge University Press.
[11] Skowronek/Glassman M. (Eds.), Formative Acts. American Politics in the Making, University of Pennsylvania Press.

[12] Granovetter M. (2017), Society and Economy: Framework and Principles, Cambridge, Harvard University Press.

[13] Fligstein N/ McAdam D. (2012) A Theory of Fields, New York (NY), Oxford University Press.

[14] Olson M. (1965), The Logic of Collective Action, Cambridge, Mass, Harvard University Press.

[15] Granovetter M.-(1985), Economic Action and Social Structure: The Problem of Embeddedness», American Journal of Sociology, 91, 3, p. 481-510.

[16] Scott J. C., (1976), The Moral Economy of the Peasant: Rebellion and Subsistence in Southeast Asia, New Haven, Yale University Press and.

[17] Popkin S. L., (1979), The Rational Peasant: The Political Economy of Rural Society in Vietnam, Berkeley (CA), University of California Press.

[18] Emirbayer M. (1997), Manifesto for a relational sociology, American journal of sociology, vol. 103, $\mathrm{n}^{\circ} 2$, p. 281-317. 